\title{
Kajian Simpang Tiga Tak Bersinyal Kariangau KM. 5,5 Kelurahan Karang Joang Balikpapan Utara Menggunakan Permodelan Vissim menjadi Simpang Bersinyal
}

\author{
Trinoko Lutfi Saputro" ${ }^{1}$ Arum Prastiyo Putri², Alnovia Suryaningsih ${ }^{3}$, Zia Sakinah Putri ${ }^{4}$, Muhammad \\ Salahuddin 5 \\ 1,2,3,4,5 Program Studi Teknik Sipil, Institut Teknologi Kalimantan, Jl Soekarno Hatta Km. 15, Balikpapan Utara \\ ${ }^{*}$ E-mail: trinokolutfisaputro@gmail.com
}

\begin{abstract}
Balikpapan as a developing city had a constant increasing in vehicle volume every year, it cause majority of traffic network in Balikpapan could not handle the increasing of vehicle volume in some of the road and intersection which cause traffic jam, one of the worst case is Kariangau intersection in km 5.5. Hopefully the result of this study will give accurate modeling and analyzing performance of Kariangau intersection and give alternative solution to increase performance of Kariangau intersection. The method that has been used in this study of Kariangau intersection is literature research, surveying, collecting data using counting machine and data analysing according to MKJI 1997 and modelling traffic flow using Vissim 9 software. The Analyzation according to MKJI 1997, average traffic flow (Q) in Kariangau intersection is 5,096 pce/hr, density (DS) 2.279, delay is $1.062 \mathrm{sec} / \mathrm{pce}$ and queue up to 252-649\%. With the implementation of traffic light in Kariangau intersection, it will decrease the average traffic flow up to 1,248 pce/hr dan density up to 0.756 or up to $67 \%$.
\end{abstract}

Keyword: density, signalized intersection, vehicle volume, vissim

\begin{abstract}
Abstrak
Balikpapan sebagai kota berkembang terus mengalami peningkatan volume kendaraan tiap tahunnya, hal ini mengakibatkan mayoritas sistem jaringan jalan Balikpapan tidak dapat lagi mengimbangi pertumbuhan volume kendaraan di beberapa lokasi jalan dan persimpangan yang mengakibatkan kemacetan, salah satunya adalah simpang Kariangau km 5,5. Hasil kajian ini diharapkan dapat memodelkan secara akurat dan menganalisa kinerja simpang Kariangau serta memberi alternatif solusi untuk meningkatkan kinerja simpang. Adapun metode yang digunakan dalam menunjang kegiatan kajian simpang tiga Kariangau meliputi kajian literatur, survey lokasi, pengambilan dan pengumpulan data menggunakan alat bantu Counting dan penganalisaan data sesuai dengan panduan MKJI tahun 1997 serta permodelan arus lalu lintas menggunakan software Vissim 9. Analisa berdasarkan panduan MKJI 1997, maka didapatkan hasil kajian terkait simpang Kariangau berupa nilai arus lintas rata-rata (Q) sebesar $5.096 \mathrm{smp} / \mathrm{jam}$, derajat kejenuhan (DS) sebesar 2,279, tundaaan simpang sebesar 1,062 det/smp dan peluang antrian sebesar 252-649\%. Dengan penerapan simpang bersinyal di persimpangan Kariangau, nilai Q dapat ditekan menjadi $1.248 \mathrm{smp} / \mathrm{jam}$ dan derajat kejenuhan (DS) sebesar 0,756 atau turun hingga $67 \%$.
\end{abstract}

Kata Kunci: derajat kejenuhan, simpang bersinyal, vissim, volume kendaraan

\section{PENDAHULUAN}

Kotamadya Balikpapan memiliki luas wilayah kurang lebih 50.330,57 ha Kotamadya Balikpapan terletak pada posisi 116,5 BT-117,5'BT dan 1,0 LS-1,5'LS, dengan batas-batas wilayah kota Balikpapan yaitu, sebelah utara berbatasan dengan Kabupaten Kutai Kartanegara, sebelah timur dan selatan berhadapan langsung dengan Selat Makasar, kemudian sebelah barat berbatasan langsung dengan Teluk Balikpapan dan Kabupaten Pasir [1].
Seiring bertumbuhnya jumlah penduduk di kota Balikpapan yang relatif tinggi dan adanya urbanisasi yang cukup deras maka hal tersebut menimbulkan bertambahnya jumlah kendaraan bermotor, mobil yang berakibat semakin menumpuknya alat transportasi pribadi hingga memunculkan dampak negatif yang sangat serius yaitu kemacetan lalu lintas kendaraan bermotor. Volume kendaraan yang semakin meningkat mengakibatkan kapasitas jalan menjadi semakin kecil jika tidak diimbangi dengan peningkatan jaringan dan kapasitas jalan 
sehingga sistem jaringan jalan di kota Balikpapan secara mayoritas sudah tidak sanggup lagi mengimbangi pertumbuhan volume kendaraan dibeberapa lokasi jalan maupun simpang yang terdapat di Kota Balikpapan. Salah satu simpang yang mengalami kemacetan adalah simpang Kariangau km 5,5.

Persimpangan jalan didefinisikan sebagai daerah umum di mana ada dua jalan atau lebih bergabung termasuk jalan dan fasilitas tepi jalan untuk pergerakan lalu-lintas di dalamnya. Persimpangan sebidang dapat dikelompokkan menurut cabangnya yaitu pertemuan sebidang bercabang tiga, pertemuan sebidang bercabang empat, dan pertemuan sebidang bercabang banyak. Menurut pengaturannya, persimpangan sebidang dibagi menjadi dua yaitu persimpangan tak sinyal, dan persimpangan dengan sinyal [2].

Simpang tiga Kariangau terletak di Kecamatan Balikpapan Utara. Pada simpang tiga tak bersinyal ini sering terjadi konflik antara kendaraan yang berbeda dari setiap lajur jalan yang ada, baik asal maupun tujuan. Berkaitan dengan hal tersebut analisa persimpangan tak bersinyal sangat diperlukan, sehingga dapat dijadikan dasar dalam menganalisis kinerja simpang tersebut.

Berdasarkan uraian yang disebutkan diatas, maka kegiatan ini bertujuan untuk memodelkan dan menganalisis kinerja simpang tiga tak bersinyal pada simpang Kariangau, serta memberikan alternatif solusi untuk meningkatkan kinerja simpang dengan melakukan perbaikan yang diperlukan untuk memperlancar arus lalu lintas pada simpang tersebut.

Batasan masalah analisis simpang bersinyal adalah data yang disimulasikan adalah simpang tiga Kariangau pada J1 Soekarno hatta, Balikpapan, skenario lalu lintas menggunakan software simulasi Vissim 9 Student Version [5], serta analisis perhitungan simpang bersinyal menggunakan MKJI tahun 1997 [3].

Analisis kinerja simpang bersinyal dilakukan menurut Manual Kapasitas Jalan Indonesia (MKJI) tahun 1997 [3] dan menggunakan pemodelan dengan program (software) Vissim 9 Student Version) yang kemudian dianalisis untuk mendapatkan nilai pelayanan simpang tersebut. Alternatif solusi untuk meningkatkan kinerja simpang kemudian diaplikasikan dalam pemodelan lebih lanjut sampai didapatkan model yang optimum dengan kinerja yang baik pada simpang Kariangau nantinya.

Menurut Morlok [4] menjelaskan bahwa jenis-jenis simpang berdasarkan dari cara pengaturannya dapat dikelompokkan menjadi 2 (dua) jenis, yaitu simpang jalan tanpa sinyal dan simpang jalan dengan sinyal. Simpang jalan dengan sinyal yaitu pemakai jalan dapat melewati simpang seharusnya dapat sesuai dengan pengoperasian sinyal lalu lintas. Jadi pemakai jalan hanya boleh lewat pada saat sinyal lalu lintas menunjukkan warna hijau pada lengan simpangnya.

Salah satu program bantu yang digunakan dalam memodelkan simpang bersinyal Kariangau adalah dengan menggunakan Vissim 9 Student Version. Vissim 9 Student Version merupakan program bantu yang digunakan pada penggunaan skala mikroskopik dan biasanya digunakan untuk analisis simulasi lalu lintas yang bersifat mendetail dan rinci, adapun rentang waktu permodelan tersebut dapat berlangsung selama 10 menit [5].

\section{METODOLOGI}

Adapun metodologi yang digunakan pada analisis simpang 3 Kariangau, akan dijelaskan pada Gambar 1 .

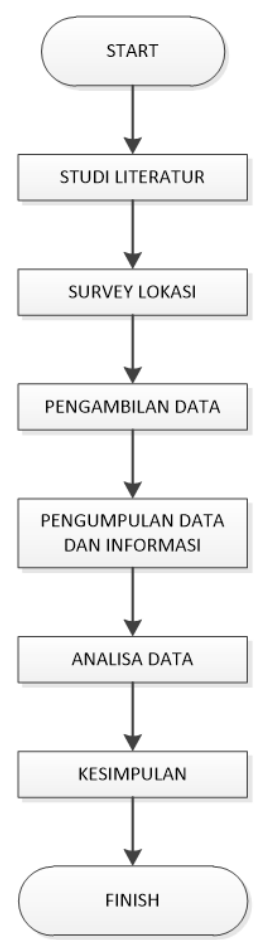

Gambar 1 Diagram alir analisis dan permodelan simpang 3 Kariangau 
Adapun penjelasan dari kegiatan analisis adalah sebagai berikut:

\section{Kegiatan survey}

Survey dilakukan pada simpang tiga Kariangau, yang terdapat di Jalan Soekarno Hatta, Km 5,5 Kelurahan Karang Joang Balikpapan Utara, melihat kondisi eksisting dari simpang tiga Kariangau dengan menggunakan Google Maps dapat terlihat pada Gambar 2.
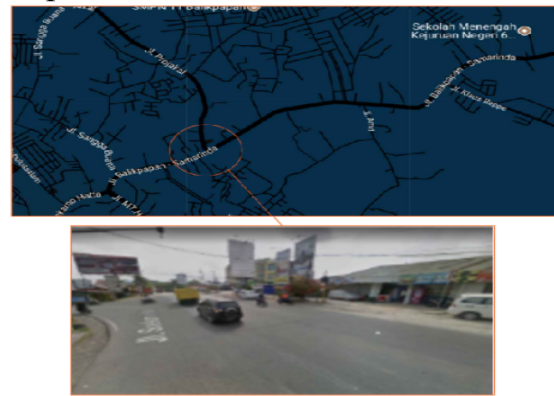

Gambar 2. Maps simpang tiga Kariangau

\section{Pengambilan Data}

Pengambilan data primer dilakukan dengan bantuan berupa alat counting yang digunakan untuk menghitung banyaknya jumlah kendaraan yang lewat di simpang tersebut. Adapun pengambilan data primer akan dijelaskan pada Gambar 3, Gambar 4, dan Gambar 5.
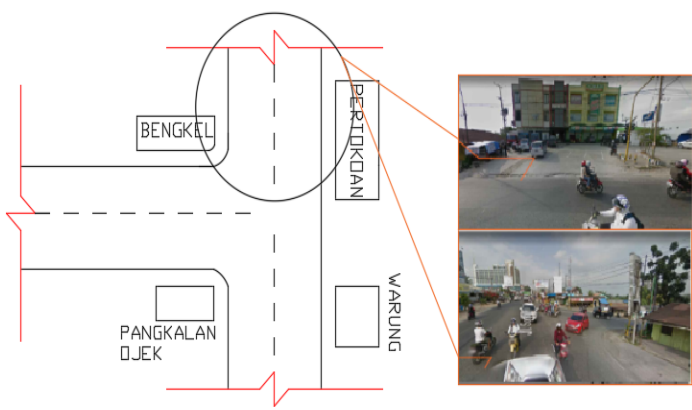

Gambar 3. Titik 1 jalan dari arah kilo

Gambar 3 merupakan titik jalan pengambilan data kendaraan yang berasal dari arah kilo menuju simpang Kariangau dan arah kota.

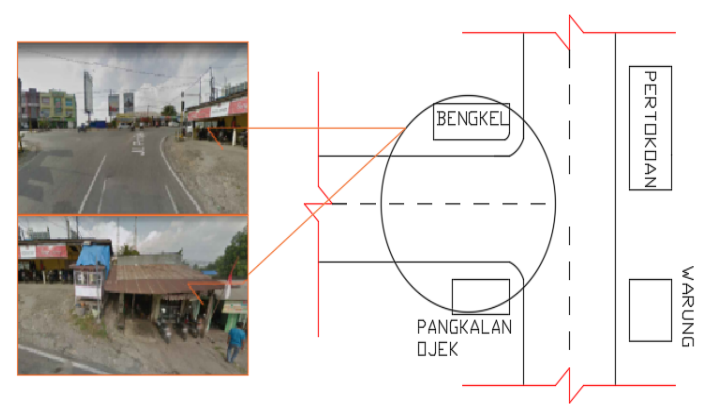

Gambar 4. Titik 2 jalan dari arah Kariangau
Gambar 4 merupakan titik jalan pengambilan data kendaraan yang berasal dari arah Kariangau menuju kilo dan daerah kota.

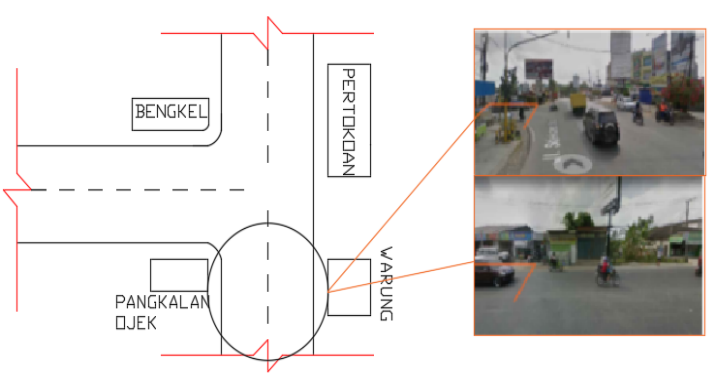

Gambar 5. Titik 3 jalan dari arah kota

Gambar 5 merupakan titik jalan pengambilan data kendaraan yang berasal dari arah kota menuju kilo dan daerah Kariangau.

\section{Pengumpulan data dan informasi}

Pengumpulan data dan informasi terdiri dari dua bagian yaitu data primer dan sekunder. Data primer meliputi data geometric jalan, data volume lalu lintas, dan data kondisi lalu lintas, kemudian untuk data sekunder terdiri dari peta kota dan data jalan, kemudian data jumlah penduduk.

\section{Analisis Data}

Data primer dan sekunder yang telah didapatkan sebelumnya kemudian akan diolah serta dianalisis menggunakan kinerja simpang bersinyal dilakukan menurut MKJI tahun 1997 [3], dan permodelan simpang bersinyal menggunakan program (software) Vissim 9 student version [5].

\section{HASIL DAN PEMBAHASAN}

Data yang digunakan untuk proses perhitungan adalah data primer. Dimana data primer merupakan data yang didapat dari pengamatan langsung dan perhitungan dilapangan, dalam hal ini lokasi penelitian di simpang tiga Kariangau pada J1 Soekarno hatta, Balikpapan, metode yang digunakan adalah berdasarkan perumusan simpang bersinyal dan tak bersinyal berdasarkan MKJI tahun 1997 [3]. Gambar 6 menjelaskan simpang Kariangau dan lebar masing-masing lajur. 


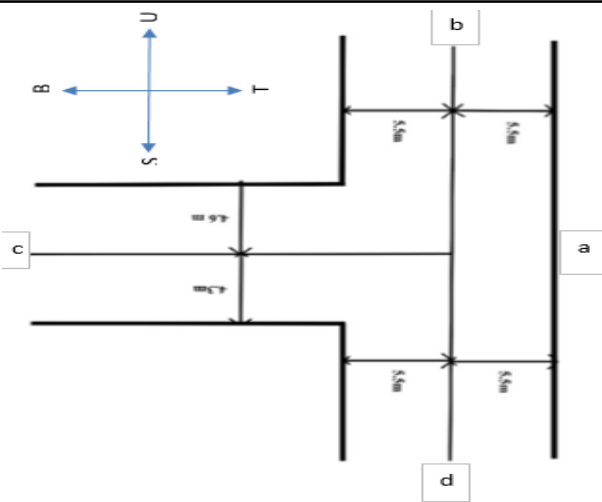

Gambar 6. Lebar lajur simpang Kariangau

\section{A. Simpang Tak Bersinyal}

Berikut adalah tabel perhitungan dari analisa simpang tak bersinyal yang terdapat di jalan soekarno Hatta km 5,5 meliputi hasil perhitungan geometrik jalan dan arus lalu lintas, lebar pendekat, kapasitas dan perilaku lalu lintas.

\section{Geometrik Jalan dan Arus Lalu Lintas}

Analisis terkait geometrik jalan dan arus lalu lintas dari simpang tak bersinyal Kariangau berdasarkan formulir USIG-I pada MKJI tahun 1997 [6], menjelaskan bahwa perhitungan untuk arus lalu lintas dilakukan per satuan jam atau lebih periode. Misalnya didasarkan pada arus lalu lintas rencana jam puncak pagi, siang, dan sore.

Arus lalu lintas untuk setiap gerakan dikonversi dari kendaraan perjam menjadi satuan mobil penumpang dengan (smp) per jam dengan menggunakan ekuivalen kendaraan penumpang (emp).

Adapun hasil perhitungan dapat terlihat pada Tabel 1.

Tabel 1 Data hasil perhitungan geometri dan arus lalu lintas di persimpangan Kariangau

\begin{tabular}{|c|c|c|c|c|c|c|c|c|c|c|c|}
\hline \multirow{2}{*}{$\begin{array}{l}\text { Arus } \mathrm{L} \text { ah } \\
\text { lintas } \\
\text { pendelat }\end{array}$} & \multirow[b]{2}{*}{$\underset{b}{A r a}$} & \multicolumn{2}{|c|}{ LV } & \multicolumn{2}{|c|}{$\mathrm{Hv}$} & \multicolumn{2}{|c|}{ MC } & \multicolumn{3}{|c|}{$\begin{array}{c}\text { Kendaranan Bermotor } \\
\text { total MN }\end{array}$} & \multirow[t]{2}{*}{$\mathrm{CM}$} \\
\hline & & $k / j$ & $\begin{array}{c}\text { emp } \\
=1 \\
\mathrm{~s} / \mathrm{j}\end{array}$ & $k^{\prime} / j$ & $\underset{\substack{\operatorname{emp} p=1, 3 s / j}}{ }$ & $\mathbf{k}_{\mathbf{j}}$ & $\begin{array}{l}\text { emp } \\
=0,5 \\
3, j\end{array}$ & $k^{k} / \mathbf{j}$ & $s / j$ & $\begin{array}{l}\text { Kassio } \\
\text { Belok }\end{array}$ & \\
\hline \multirow{3}{*}{$\begin{array}{c}\text { Jalan } \\
\text { Utana A }\end{array}$} & ST & 591 & 591 & 74 & 96,2 & $\begin{array}{c}1775 \\
4\end{array}$ & 877 & $\begin{array}{c}241 \\
9\end{array}$ & $\begin{array}{l}156 \\
4,2\end{array}$ & & 1 \\
\hline & $\mathrm{RT}$ & 33 & 33 & 44 & 57,2 & 76 & 38 & 153 & $\begin{array}{c}128, \\
2\end{array}$ & 0,08 & 0 \\
\hline & $\begin{array}{c}\text { Tot } \\
\text { al }\end{array}$ & 624 & ${ }_{624}$ & 118 & 153,4 & ${ }_{0}^{183}$ & 915 & $\frac{257}{2}$ & ${ }_{2,4}^{169}$ & & 1 \\
\hline \multirow{3}{*}{$\begin{array}{l}\text { Jalan } \\
\text { Utama B }\end{array}$} & ST & 521 & 521 & 101 & 131,3 & ${ }_{0}^{178}$ & 890 & $\frac{240}{2}$ & $\frac{154}{2.3}$ & & 3 \\
\hline & LT & 206 & 206 & 39 & 50,7 & $\frac{121}{1}$ & $\begin{array}{c}605, \\
5\end{array}$ & $\frac{145}{6}$ & $\begin{array}{c}862, \\
2\end{array}$ & & 0 \\
\hline & $\begin{array}{l}\text { Tot } \\
\text { al }\end{array}$ & 727 & 727 & 140 & 182 & $\frac{299}{1}$ & $\begin{array}{l}149 \\
5,5\end{array}$ & 385 & 240 & & 3 \\
\hline $\begin{array}{c}\text { Total } \\
\text { Jalan } \\
\text { Utama } \\
A+B\end{array}$ & & $\frac{135}{1}$ & $\frac{135}{1}$ & 268 & 335,4 & ${ }_{1}^{482}$ & ${ }_{0,5}^{241}$ & ${ }_{0}^{643}$ & $\begin{array}{l}409 \\
6.9\end{array}$ & 0,43 & 4 \\
\hline \multirow{3}{*}{$\begin{array}{l}\text { Jalan } \\
\text { Manor C }\end{array}$} & RT & 265 & 255 & 59 & 76,7 & ${ }_{9}^{108}$ & $\frac{54,5}{5}$ & ${ }_{3}^{140}$ & $\frac{876,}{2}$ & $0, s \mathrm{~s}$ & 0 \\
\hline & LT & 26 & 26 & 21 & 27,3 & 141 & 70,5 & 188 & $\begin{array}{l}123, \\
8\end{array}$ & 0,12 & 0 \\
\hline & $\begin{array}{c}\text { Tot } \\
\text { al }\end{array}$ & 281 & 281 & so & 104 & $\frac{123}{0}$ & 615 & $\frac{150}{1}$ & $0_{0}^{100}$ & & 0 \\
\hline $\begin{array}{c}\text { Totalal } \\
\text { Jalan } \\
\text { Minor C }\end{array}$ & & 281 & 281 & $s_{0}$ & 104 & $\begin{array}{c}123 \\
0\end{array}$ & 615 & $\begin{array}{c}150 \\
1\end{array}$ & $\begin{array}{c}100 \\
0\end{array}$ & 1,00 & 0 \\
\hline \multirow{3}{*}{$\begin{array}{c}\text { Utama } \\
\text { Minaor }\end{array}$} & LT & 232 & 232 & 60 & 78 & $\frac{135}{2}$ & 676 & $\begin{array}{l}164 \\
4\end{array}$ & 986 & 0 & 0 \\
\hline & ST & $\frac{111}{21}$ & ${ }_{2}^{111}$ & 175 & 227,5 & 353 & ${ }^{176}$ & ${ }_{1}^{482}$ & $\begin{array}{l}310 \\
6.5\end{array}$ & & 4 \\
\hline & $\mathrm{RT}$ & 288 & 288 & 103 & 133.9 & $\frac{116}{5}$ & $\begin{array}{c}582, \\
5\end{array}$ & $\frac{155}{6}$ & $\begin{array}{l}100 \\
4,4\end{array}-10$ & 0,20 & 0 \\
\hline $\begin{array}{l}\text { Vtama }+ \\
\text { Minoor }\end{array}$ & & 163 & 163 & 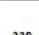 & & 605 & 302 & 302 & 509 & & \\
\hline & & & & \multicolumn{4}{|c|}{$\begin{array}{l}\text { Rasio Jalan MI } \\
\text { NanortTotal }\end{array}$} & & $\begin{array}{l}0,19 \\
619 \\
67\end{array}$ & LMM & 0.00 \\
\hline
\end{tabular}

\section{Lebar Pendekat dan Tipe Simpang}

Adapun analisis terkait lebar pendekat dan tipe simpang Kariangau berdasarkan kondisi eksistingnya dan akan diklasifikasikan dapat diketahui bahwa tipe simpang Kariangau adalah 322. Berikut adalah hasil dari perhitungan analisis simpang berdasarkan kategori yang terdapat pada fomulir USIG-II MKJI 1997 [7], dapat terlihat pada Tabel 2.

Tabel 2. Lebar pendekat dan tipe simpang

\begin{tabular}{|c|c|c|c|c|c|c|c|c|c|c|}
\hline \multirow{3}{*}{$\begin{array}{l}\text { Jumlah } \\
\text { Lengan } \\
\text { Simpang }\end{array}$} & \multicolumn{7}{|c|}{ Lebar Pendekat (m) } & \multicolumn{2}{|c|}{ Jumlah Lajur } & \multirow{3}{*}{$\begin{array}{c}\text { Tipe } \\
\text { Simpa } \\
\text { ng }\end{array}$} \\
\hline & \multicolumn{3}{|c|}{ Jalan Minor } & \multicolumn{3}{|c|}{ Jalan Utama } & \multirow{2}{*}{$\begin{array}{c}\text { Lebar } \\
\text { Pendekat } \\
\text { Rata-rata } \\
\text { Wl }\end{array}$} & \multirow{2}{*}{$\begin{array}{c}\text { Jala } \\
\text { n } \\
\text { Min } \\
\text { or }\end{array}$} & \multirow{2}{*}{$\begin{array}{l}\text { Jalan } \\
\text { Utama }\end{array}$} & \\
\hline & W & W & W & $\begin{array}{l}\text { W } \\
\text { b }\end{array}$ & $\begin{array}{l}\text { W } \\
d\end{array}$ & $\begin{array}{l}\text { W } \\
\text { bd }\end{array}$ & & & & \\
\hline 3 & & $\begin{array}{l}4, \\
45\end{array}$ & $\begin{array}{c}2,2 \\
3\end{array}$ & $\begin{array}{l}5, \\
5\end{array}$ & $\begin{array}{l}5, \\
5\end{array}$ & 5,5 & 5,22 & 2 & 2 & 322 \\
\hline
\end{tabular}

\section{Kapasitas}

Menurut MKJI [8], kapasitas adalah arus lalu-lintas maksimum yang dapat dipertahankan pada kondisi tertentu (geometrik, arus lalu-lintas dan lingkungan), kapasitas total untuk seluruh lengan simpang adalah hasil perkalian antara kapasitas dasar (Co) yaitu kapasitas pada kondisi tertentu (ideal) dan faktor-faktor penyesuaian (F) dengan memperhitungkan kondisi lapangan terhadap kapasitas. Untuk mengetahui nilai kapasitas dapat digunakan Pers. (1) pada MKJI [8].

$\mathrm{C}=\mathrm{Co} \times \mathrm{FW} \times \mathrm{FM} \times \mathrm{FCS} \times \mathrm{FRSU} \times \mathrm{FLT} \times$

FRT $\times$ FMI Pers. (1)

Hasil analisis terkait kapasitas jalan simpang Kariangau berdasarkan formulir USIG-II pada MKJI [7], seperti terlihat pada Tabel 3.

Tabel 3. Kapasitas

\begin{tabular}{|c|c|c|c|c|c|c|c|c|}
\hline $\begin{array}{c}\text { Kapasit } \\
\text { as } \\
\text { Dasar } \\
\text { Co } \\
\text { (Smp/Ja } \\
\text { m) }\end{array}$ & $\begin{array}{c}\text { Leba } \\
r \\
\text { Pend } \\
\text { ekat } \\
\text { Rata- } \\
\text { Rata } \\
\text { Fw }\end{array}$ & $\begin{array}{c}\text { Medi } \\
\text { an } \\
\text { Jalan } \\
\text { Utam } \\
\text { a Fm }\end{array}$ & $\begin{array}{c}\text { Ukur } \\
\text { an } \\
\text { Kota } \\
\text { Fcs }\end{array}$ & $\begin{array}{c}\text { Ham } \\
\text { batan } \\
\text { Samp } \\
\text { ing } \\
\text { Frsu }\end{array}$ & $\begin{array}{c}\text { Belok } \\
\text { Kiri } \\
\text { Flt }\end{array}$ & $\begin{array}{c}\text { Belo } \\
\text { k } \\
\text { Kan } \\
\text { an } \\
\text { Frt }\end{array}$ & $\begin{array}{c}\text { Rasio } \\
\text { Minor } \\
\text { total } \\
\text { FMII }\end{array}$ & $\begin{array}{c}\text { Kapa } \\
\text { sitas } \\
\text { C } \\
(\mathrm{Smp} / \\
\mathrm{Jam})\end{array}$ \\
\hline 2700 & $\begin{array}{c}1,125 \\
2\end{array}$ & 1 & 0,82 & 0,95 & 1,275 & $\begin{array}{c}0,74 \\
0\end{array}$ & 1,002 & $\begin{array}{c}2236 \\
510\end{array}$ \\
\hline
\end{tabular}

Adapun nilai kapasitas yang didapat pada simpang tidak bersinyal Kariangau sebesar $2236,510 \mathrm{smp} / \mathrm{jam}$.

\section{Perilaku lalu lintas}

Adapun hasil perhitungan terkait perilaku lalu lintas seperti pada formulir USIG-II MKJI [7], dapat dijelaskan pada Tabel 4. 


\begin{tabular}{cccccccc}
\multicolumn{7}{c}{ Tabel. 4 Perilaku lalu lintas } \\
\hline Arus & Deraj & Tunda & Tunda & Tundaa & Tunda & Tun & Pelua \\
Lalu & at & an & an & n Lalu & an & daa & ng \\
Lintas & Kejen & Lalu & Lalu & Lintas & Geom & n & Antria \\
Q & uhan & Lintas & Lintas & Minor & etrik & Sim & n QP \\
(Smp/ & DS & Simpa & Utama & Dmi & Simpa & pan & \\
Jam) & & ng DT & Dma & & ng DG & g D & \\
\hline $\mathbf{5 0 9 6 , 6}$ & $\mathbf{2 , 2 7 9}$ & $-2,938$ & $-2,593$ & $-2,429$ & 4 & 1,06 & 648,82 \\
\cline { 5 - 9 } & & & & & & 2 & 251,98 \\
\hline
\end{tabular}

\section{B. Simpang Bersinyal}

\section{Data Geometrik}

Data geometrik ini berisikan tentang kode pendekat, tipe lingkungan, tingkat hambatan damping, median, kelandaian, belok kiri langsung, jarak kendaraan parkir, dan lebar pendekat berdasarkan kategori yang ada pada fomulir SIG-I MKJI 1997 [9]. Pendataan geometrik pada penelitian ini dilakukan secara manual, yaitu pengukuran langsung dilapangan. Adapun data yang didapat dari hasil pengamatan dapat terlihat pada Tabel 5 .

\begin{tabular}{|c|c|c|c|c|c|c|c|c|c|}
\hline \multirow{2}{*}{$\begin{array}{l}\text { Kode } \\
\text { Pendek } \\
\text { at }\end{array}$} & \multirow{2}{*}{$\begin{array}{l}\text { Tipe } \\
\text { Lingku } \\
\text { ngan } \\
\text { Jalan }\end{array}$} & \multirow{2}{*}{$\begin{array}{l}\text { Hamba } \\
\text { tan } \\
\text { Sampin } \\
\mathrm{g}\end{array}$} & \multirow{2}{*}{$\begin{array}{l}\text { Medi } \\
\text { an }\end{array}$} & \multirow{2}{*}{$\begin{array}{l}\text { lok } \\
\text { Kiri } \\
\text { Langs } \\
\text { ung }\end{array}$} & \multirow{2}{*}{$\begin{array}{l}\text { Jarak } \\
\text { Kendar } \\
\text { aan } \\
\text { Parkir }\end{array}$} & \multicolumn{4}{|c|}{ Lebar Pendekat } \\
\hline & & & & & & $\mathrm{Wa}$ & $\mathrm{We}$ & $\begin{array}{l}\text { Wlto } \\
\mathrm{r}\end{array}$ & Wex \\
\hline $\mathrm{U}$ & Com & $R$ & T & $\mathrm{T}$ & - & 11 & 5,5 & - & 5,5 \\
\hline B & Com & $R$ & $\mathrm{~T}$ & T & - & 8,9 & 4,6 & - & 4,3 \\
\hline S & Com & $R$ & T & T & - & 11 & 5,5 & - & 5,5 \\
\hline
\end{tabular}

Pada Tabel 5 menampilkan data geometrik dari perencanaan simpang tiga bersinyal Kariangau dengan pendekat $U$ sebagai jalan arah Balikpapan - Samarinda, pendekat B sebagai jalan arah Kariangau, serta pendekat $S$ sebagai jalan menuju pusat Kota Balikpapan.

\section{Arus Jenuh}

Dengan menggunakan perumusan pada formulir SIG-IV MKJI 1997 [10], diperoleh nilai arus jenuh simpang seperti terlihat pada Tabel 6.

Tabel 5. Data geometrik

\begin{tabular}{ccccccccccc} 
& \multicolumn{1}{c}{ Tabel 6. Perhitungan arus jenuh pada saat jam puncak terlindung } \\
\hline Pendekat & $\begin{array}{c}\text { We } \\
(\mathbf{m})\end{array}$ & $\begin{array}{c}\text { So } \\
(\mathbf{S m p} / \mathbf{J a m})\end{array}$ & \multicolumn{6}{c}{ Faktor Penyesuaian } & S (Smp/Jam) \\
\cline { 5 - 9 } & & & Fcs & Fsf & Fg & Fp & Frt & Flt & \\
\hline U & 5.5 & 3300 & 0,82 & 0,93 & 1 & 1 & 1,02 & 1 & 2559,7 \\
\hline B & 4.6 & 2760 & 0,82 & 0,93 & 1 & 1 & 1,25 & 1 & 2636,1 \\
\hline S & 5.5 & 3300 & 0,82 & 0,93 & 1 & 1 & 1,09 & 0,808 & 2222,1
\end{tabular}

Pada Tabel 6 menampilkan data untuk menghitung arus jenuh pada masing-masing kode pendekat yang telah ditentukan sebelumnya. Berdasarkan rumus (24) pada MKJI [11], dapat digunakan Pers. (2).

$S=S o . F C S . F S F . F P . F G . F R T . F L T$

dimana:

$S=$ Arus jenuh nyata (smp/jam hijau);

$S o=$ Arus jenuh dasar (smp/jam hijau);

$F C S=$ Faktor koreksi ukuran kota;

$F S F=$ Faktor penyesuaian hambatan samping;

$F P=$ Faktor penyesuaian parkir tepi jalan;

$F G=$ Faktor penyesuaian akibat gradien jalan;

$F R T=$ Faktor koreksi belok kanan;

$F L T=$ Faktor penyesuaian belok kiri.

Sehingga didapat nilai arus jenuh untuk perencanaan simpang bersinyal Kariangau sebesar 2559,7 smp/jam.

\section{Rasio Arus jenuh}

Dari hasil perhitungan nilai arus jenuh kemudian dapat diperoleh nilai Rasio Arus (FR) dan nilai Rasio Fase, maka diperoleh Rasio Arus Simpang (IFR). Hal perhitungan rasio arus jenuh kondisi eksisting untuk seluruh pendekat sesuai dengan formulir SIGIV MKJI [10], dapat dilihat pada Tabel 7.

Tabel 7. Rasio arus jenuh

\begin{tabular}{|c|c|c|c|c|c|c|c|}
\hline $\begin{array}{c}\text { Pen } \\
\text { dekat }\end{array}$ & $\begin{array}{c}\mathbf{Q} \\
\text { (Smp/ } \\
\text { Jam) }\end{array}$ & S & $\begin{array}{c}\text { FR } \\
(\mathbf{Q} / \mathbf{S})\end{array}$ & Frcrit & Cua & LTI & PRi \\
\hline $\mathbf{U}$ & 1418,1 & 2559,76 & 0,554 & 0,352 & 35,511 & 12,0 & 0,352 \\
\hline B & 403,25 & 2636,15 & 0,153 & 0,097 & 25,479 & 12,0 & 0,097 \\
\hline $\mathrm{S}$ & 1923,25 & 2222,14 & 0,865 & 0,550 & 51,158 & 12,0 & 0,550 \\
\hline
\end{tabular}

Pada Tabel 7 menampilkan rasio arus jenuh dengan menggunakan persamaan pada MKJI [7], sehingga didapat nilai rasio arus jenuh (FR) sebesar 0,554 untuk pendekat U, 0,153 untuk pendekat B, 0,865 untuk pendekat $\mathrm{S}$.

\section{Kapasitas dan Derajat Kejenuhan}

Kapasitas (C) diperoleh dengan perkalian arus jenuh dengan rasio hijau $(\mathrm{g} / \mathrm{c})$ pada masing-masing pendekat, sesuai dengan rumus pada (32) MKJI [12] yang ditunjukkan dalam Pers. (3).

$$
\mathrm{C}=\mathrm{S} \times \mathrm{g} / \mathrm{c}
$$


Derajat kejenuhan (DS) diperoleh dari hasil bagi arus dengan kapasitas dengan rumus (33) pada MKJI [12] seperti dalam Pers. (4).

$$
\mathrm{DS}=\mathrm{Q} / \mathrm{C}
$$

Hasil perhitungan kapasitas dan derajat kejenuhan kondisi eksisting untuk seluruh pendekat berdasarkan formulir SIG-IV pada MKJI [10], dapat dilihat pada Tabel 8 akan didapatkan nilai kapasitas dan derajat kejenuhan pada masing-masing pendekat.

Tabel 8. Kapasitas dan derajat kejenuhan

\begin{tabular}{cccccc}
\hline $\begin{array}{c}\text { Pen } \\
\text { dekat }\end{array}$ & $\begin{array}{c}\text { g } \\
\text { (detik) }\end{array}$ & $\begin{array}{c}\text { c } \\
\text { (detik) }\end{array}$ & $\begin{array}{c}\text { Q } \\
\text { (Smp/Jam) }\end{array}$ & $\begin{array}{c}\text { C } \\
\text { (Smp/Jam) }\end{array}$ & DS \\
\hline U & 37 & 61,0 & 1418,1 & 1552,644 & 0,913 \\
\hline B & 24 & 61,0 & 403,25 & 1037,173 & 0,389 \\
\hline S & 52 & 58,0 & 1923,3 & 1992,260 & 0,965
\end{tabular}

\section{Panjang Antrian}

Hasil perhitungan panjang antrian kondisi eksisting untuk seluruh pendekat berdasarkan pada formulir SIG-V MKJI [13], dapat dijelaskan pada Tabel 9.

Tabel 9. Hasil penyesuaian Nqmaks

\begin{tabular}{cccccc}
\hline $\begin{array}{c}\text { Pen } \\
\text { dekat }\end{array}$ & $\begin{array}{c}\text { NQ1 } \\
\text { (Smp) }\end{array}$ & $\begin{array}{c}\text { NQ2 } \\
\text { (Smp) }\end{array}$ & $\begin{array}{c}\text { Panjang } \\
\text { Antrian } \\
\text { NQ1+NQ2 } \\
\text { (Smp) }\end{array}$ & $\begin{array}{c}\text { Nqm } \\
\text { ax }\end{array}$ & $\begin{array}{c}\text { Panjang } \\
\text { Antrian QL } \\
\text { (m) }\end{array}$ \\
\hline U & 4,473 & 21,197 & 25,670 & 30 & 109,091 \\
\hline B & 0,000 & 4,893 & 4,893 & 8 & 34,783 \\
\hline S & 10,33 & 23,831 & 34,169 & 40 & 145,455 \\
\hline
\end{tabular}

Pada tabel 9 didapatkan nilai panjang antrian untuk pendekat $U$ sebesar $109 \mathrm{~m}$, pendekat B sebesar $34,783 \mathrm{~m}$, serta untuk pendekat $\mathrm{S}$ panjang antriannya sebesar $145,455 \mathrm{~m}$.

\section{Kendaraan Terhenti (NS)}

Berdasarkan formulir SIG-V MKJI [13], angka henti bersebagai jumlah rata-rata per smp untuk perancangan dihitung dengan rumus (39) pada MKJI [14], seperti ditunjukkan Pers. (5).

$$
\mathrm{NS}=0,9 * \mathrm{NQ} / \mathrm{Q} . \mathrm{c} * 3600 \text {....Pers. (5) }
$$

dimana:

$\mathrm{c}=$ waktu siklus (detik)

$\mathrm{Q}=$ arus lalu lintas (smp/jam)
Perhitungan jumlah kendaraan terhenti (Nsv) masing-masing pendekat dihitung dengan menggunakan rumus (40) pada MKJI [14], seperti dalam Pers. (6).

$$
\mathrm{Nsv}=\mathrm{Q} * \mathrm{NS}
$$

Sehingga diperoleh nilai kendaraan terhenti seperti dijelaskan pada Tabel 10.

\begin{tabular}{|c|c|c|c|c|c|c|}
\hline $\begin{array}{l}\text { Pen } \\
\text { dekat }\end{array}$ & NQ & DT & DG & $\begin{array}{c}\text { D = } \\
\text { DT + } \\
\text { DG }\end{array}$ & $\begin{array}{c}\text { D x Q } \\
(\mathrm{Det} / \mathrm{Sm} \\
\text { p) }\end{array}$ & $\begin{array}{c}\text { Dsimp } \\
\text { (Det/Smp } \\
\text { ) }\end{array}$ \\
\hline $\mathbf{U}$ & 25,67 & 20,95 & 5,924 & 26,881 & 38119,47 & 25,500930 \\
\hline B & 4,893 & 13,24 & 5,924 & 19,172 & 7731,115 & \\
\hline $\mathrm{S}$ & 34,16 & 20,98 & 4,823 & 25,811 & 49640,19 & \\
\hline
\end{tabular}

Tabel 10. Perhitungan angka henti dan jumlah kendaraan terhenti

Dari hasil analisis tersebut, maka data eksisting simpang tak bersinyal Kariangau dimodelkan ke dalam bentuk simpang bersinyal dengan menggunakan Vissim 9 student version. Pada aplikasi ini digunakan data jumlah kendaraan/jam serta hasil survey hasil rata-rata kecepatan kendaraan seperti terlihat pada Tabel 11.

\begin{tabular}{ll}
\multicolumn{2}{c}{ Tabel 11. Data kecepatan/jam } \\
\hline Kendaraan & Kecepatan/jam \\
\hline MC & 40 \\
\hline LV & 29 \\
\hline HV & 28,7 \\
\hline
\end{tabular}

Seperti terlihat pada Gambar 7 dan Gambar 8 berupa simpang Kariangau kondisi eksisting, kemudian Gambar 9 dan Gambar 10 berupa model simpang bersinyal Kariangau.

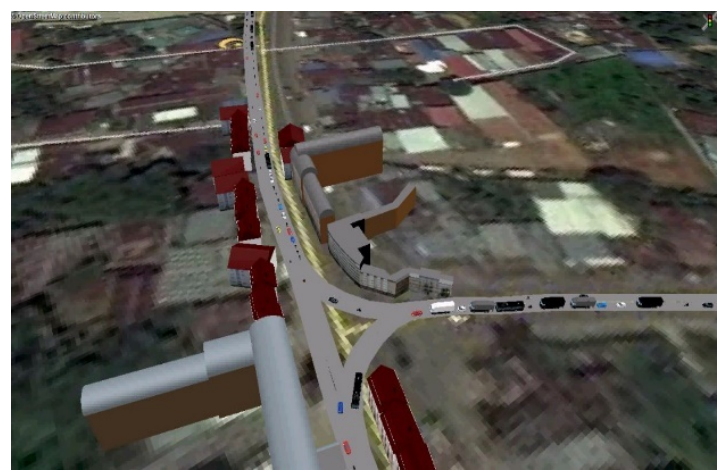

Gambar 7. Tampak atas model Vissim 9 Student Version simpang tak bersinyal 
Pada Gambar 7 merupakan hasil tampak atas kondisi eksisting simpang tak bersinyal Kariangau dengan permodelan aplikasi vissim 9 student version.

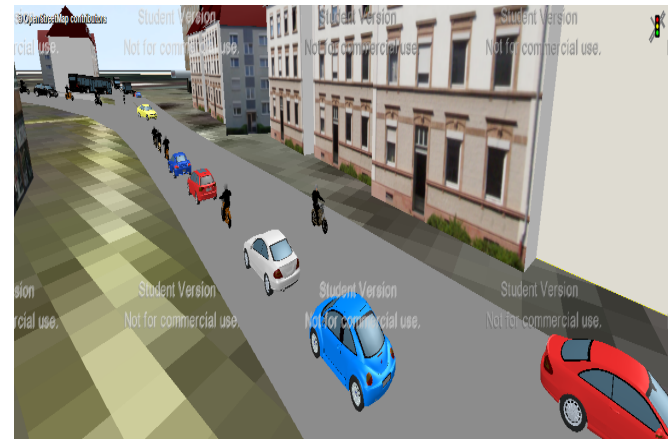

Gambar 8. Tampak samping model Vissim 9 Student Version simpang tak bersinyal

Pada Gambar 8 merupakan tampak samping kondisi eksisting simpang tak bersinyal Kariangau dengan permodelan aplikasi Vissim 9 Student Version.

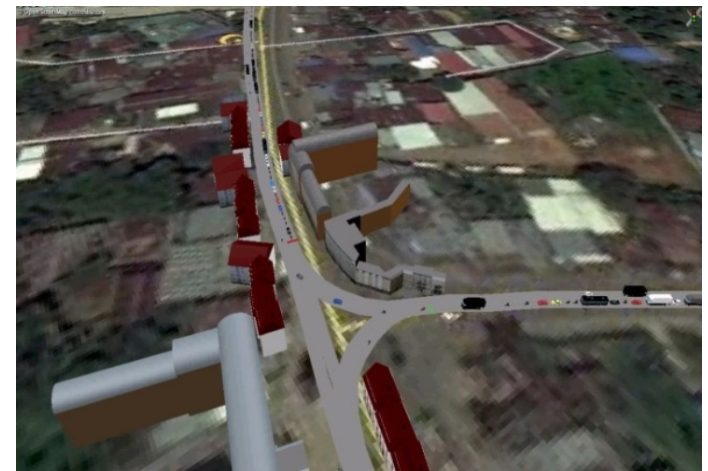

Gambar 9. Tampak atas model Vissim 9 Student Version dengan simpang bersinyal

Pada Gambar 9 merupakan tampak atas model perencanaan skenario simpang bersinyal pada simpang tiga Kariangau dengan permodelan aplikasi Vissim 9 student version.

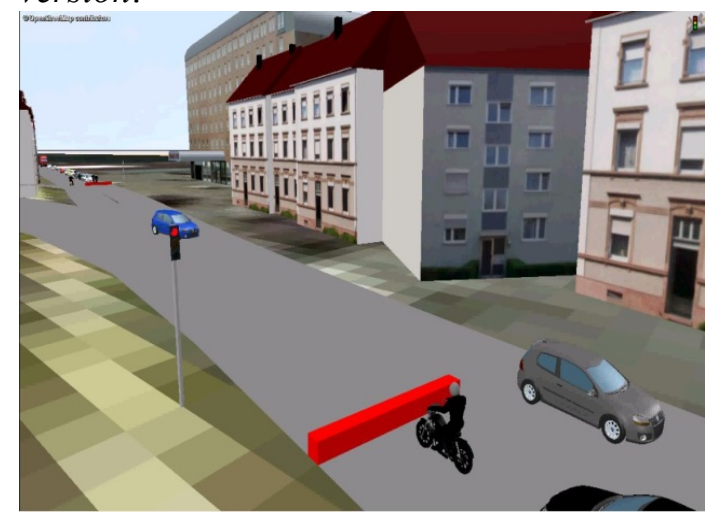

Gambar 10. Tampak samping model Vissim 9 Student Version dengan simpang
Pada Gambar 10 merupakan tampak samping model perencanaan skenario simpang bersinyal pada simpang tiga Kariangau dengan permodelan aplikasi Vissim 9 Student Version.

Adapun hasil dari analisis simpang bersinyal dengan menggunakan aplikasi Vissim 9 Student Version adalah didapatkan permodelan lalu lintas yang terjadi dari perencanaan simpang bersinyal di Kariangau sehingga dapat diketahui kefektifannya dari simpang biasa diubah menjadi simpang bersinyal. Adapun rentang waktu permodelan tersebut dapat berlangsung selama 10 menit.

\section{KESIMPULAN}

Dari kajian yang telah dilakukan terhadap Simpang Tiga tak bersinyal Kariangau Km. 5,5 Karang Joang Balikpapan Utara didapatkan hasil perhitungan menggunakan panduan MKJI berupa arus lalu lintas (Q) sebesar 5096,6 smp/jam, derajat kejenuhan (DS) sebesar 2,279, tundaan simpang (D) sebesar 1,062 det/smp, serta peluang antrian memiliki rentang sebesar 252649\%. Oleh karena itu, direncanakan permodelan Simpang Tiga Kariangau dengan model simpang bersinyal dengan hasil perhitungan menggunakan rumus MKJI sehingga didapat nilai arus lalu lintas rata-rata (Q) sebesar 1248,2 smp/jam, kapasitas ratarata (C) sebesar 1527,4 smp/jam, serta derajat kejenuhan rata-rata (DS) sebesar 0,756. Hal ini membuktikan bahwa pengkajian simpang Kariangau menggunakan simpang bersinyal telah menurunkan jumlah derajat kejenuhan sebesar 1,523 atau sekitar 67\%. Kemudian hasil dari analisis simpang bersinyal dengan menggunakan aplikasi vissim 9 student version adalah didapatkan permodelan lalu lintas yang terjadi dari perencanaan simpang bersinyal di Kariangau sehingga dapat diketahui keefektifannya dari simpang biasa diubah menjadi simpang bersinyal.

\section{SARAN}

Pada jam-jam tertentu diperlukan bantuan penanganan petugas yang berwajib untuk membantu mengatur lalu lintas kendaraan.

Perlu adanya rekayasa lalu lintas berupa penambahan traffict light. Hal ini dilihat dari rekayasa yang dilakukan,yaitu berupa sebuah rekayasa menggunakan perhitungan simpang bersinyal. Dimana dapat terlihat DS rata-rata 
menjadi lebih kecil dari perhitungan simpang tak bersinyal yaitu 0,756 .

\section{UCAPAN TERIMAKASIH}

Paper ini telah kami susun dengan maksimal dan mendapatkan bantuan dari berbagai pihak. Tidak lupa kami ucapkan banyak terima kasih kepada Bapak Muhammad Hadid, ST., MT., yang telah memberikan banyak saran serta masukan, kemudian terimakasih kepada bapak Sigit Prasetya yang telah memberikan pelatihan terkait aplikasi Vissum serta semua pihak yang terlibat dalam penyusunan full paper ini.

\section{DAFTAR PUSTAKA}

[1] Anonim, "Profil Daerah Kabupaten dan Kota”. Jakarta: Kompas, 2003, hal. 448.

[2] C. Jotin Khisty \& B. Kent Lall "Dasardasar Rekayasa Transportasi”, jilid 1. Jakarta: Erlangga, hal. 274.

[3] Direktorat Jenderal Bina Marga. "Manual Kapasitas Jalan Indonesia”. Jakarta: Bina Karya, 1997.

[4] Morlok, E. K. "Pengantar Teknik dan Perencanaan Transportasi (terjemahan John K. Naimin)". Jakarta: Erlangga, 1998.

[5] Anonim. "PTV VISION. PTV VISSIM 9 User Manual”. Karlsruhe, Germany: PTV AG: 2016.

[6] Direktorat Jenderal Bina Marga. "Manual Kapasitas Jalan Indonesia". Jakarta: Bina Karya, 1997, hal. 3-46.

[7] Direktorat Jenderal Bina Marga. "Manual Kapasitas Jalan Indonesia”. Jakarta: Bina Karya, 1997, hal. 3-47.

[8] Direktorat Jenderal Bina Marga. "Manual Kapasitas Jalan Indonesia”. Jakarta: Bina Karya, 1997, hal. 3-39.

[9] Direktorat Jenderal Bina Marga. "Manual Kapasitas Jalan Indonesia”. Jakarta: Bina Karya, 1997, hal. 2-71.

[10] Direktorat Jenderal Bina Marga. "Manual Kapasitas Jalan Indonesia”. Jakarta: Bina Karya, 1997, hal. 2-74.
[11] Direktorat Jenderal Bina Marga. "Manual Kapasitas Jalan Indonesia”. Jakarta: Bina Karya, 1997, hal. 2-56.

[12] Direktorat Jenderal Bina Marga. "Manual Kapasitas Jalan Indonesia”. Jakarta: Bina Karya, 1997, hal. 2-61.

[13] Direktorat Jenderal Bina Marga. "Manual Kapasitas Jalan Indonesia”. Jakarta: Bina Karya, 1997, hal. 2-75.

[14] Direktorat Jenderal Bina Marga. "Manual Kapasitas Jalan Indonesia”. Jakarta: Bina Karya, 1997, hal. 2-67. 